\title{
Characterization of Rhizoctonia spp. Recovered from Crop Plants Used in Rotational Cropping Systems in the Western Cape Province of South Africa
}

\author{
Y. T. Tewoldemedhin, University of Stellenbosch, Department of Plant Pathology, Matieland 7602, Stellenbosch, \\ South Africa; S. C. Lamprecht, University of Stellenbosch, Department of Plant Pathology and Plant Protection \\ Research Institute (ARC), Private Bag X5017, Matieland 7599, Stellenbosch, South Africa; A. McLeod, University \\ of Stellenbosch, Department of Plant Pathology; and M. Mazzola, United States Department of Agriculture- \\ Agricultural Research Service, Tree Fruit Research Laboratory, Wenatchee, WA 98801
}

\begin{abstract}
Tewoldemedhin, Y. T., Lamprecht, S. C., McLeod, A., and Mazzola, M. 2006. Characterization of Rhizoctonia spp. recovered from crop plants used in rotational cropping systems in the Western Cape province of South Africa. Plant Dis. 90:1399-1406.

Isolates of Rhizoctonia spp. associated with barley, canola, clover, lucerne, lupin, annual Medicago spp. (medic), and wheat were recovered during the conduct of a 4-year (2000 to 2003) crop rotation trial in the Western Cape province of South Africa. These isolates were characterized by determining their anastomosis group (AG), in vitro optimum growth temperature, and pathogenicity toward emerging and 14-day-old seedlings of all the aforementioned crops. During the 4-year rotational trial, 428 Rhizoctonia isolates, in all, were obtained. The most abundant multinucleate AG was AG-4 HG-II (69\%), followed by AG-2-1 (19\%), AG-3 (8\%), AG-2-2 (2\%), and AG-11 (2\%). The population of binucleate Rhizoctonia spp. comprised AG-K (53\%), AG-A (10\%), AG-I (5\%), and unidentified AGs (32\%). The optimal time for isolating Rhizoctonia spp. was found to be at the flowering or seedpod stage ( 20 to 22 weeks after planting). Temperature studies showed that isolates belonging to AG-2-2, AG-4 HG-II, and AG-K had significantly higher optimum growth temperatures than those from other AGs. In pathogenicity assays conducted on emerging as well as 14-day-old seedlings, isolates of AG-2-2 and AG-4 HG-II were the most virulent on all crops. Rhizoctonia solani AG-2-1 was highly virulent on canola, moderately virulent on medic and lupin, weakly virulent on lucerne and barley, and nonpathogenic on wheat. AG-11 isolates were moderate to weakly virulent on all crops, with the exception of barley and wheat. AG-3 was weakly virulent on canola, lupin, and medic. AG-K was the only binucleate Rhizoctonia sp. capable of inciting disease in our assays. This is the first comprehensive study to elucidate the identity and potential importance of Rhizoctonia spp. as a yield limiting factor in crop production systems in the Western Cape province of South Africa.
\end{abstract}

Additional keywords: sequence analysis

Plant-pathogenic Rhizoctonia spp. occur worldwide and are economically important pathogens on vegetable and field crops, turf grasses, ornamentals, and fruit and forest trees $(1,2,43)$. Among Rhizoctonia spp., the multinucleate species complex Rhizoctonia solani has been studied most extensively, having a host range of more than 250 plant species and being capable of inciting disease under diverse environmental conditions. Isolates of $R$. solani are separated by hyphal incompatibility into anastomosis groups (AGs), with the level of host specificity varying widely among AGs (2). Currently, $R$. solani can be divided into 14 anastomosis groups: AG-1 to AG-10, AG-BI (42), AG-11 (8), AG-12 (7), and AG-13 (6). Several AGs have been

Corresponding author: S. C. Lamprecht

E-mail: lamprechts@arc.agric.za

Accepted for publication 5 June 2006.

DOI: 10.1094/PD-90-1399

(C) 2006 The American Phytopathological Society subdivided further into subgroups that differ for one or more biochemical, genetic, or pathogenic characteristics $(13,26)$. $R$. solani can adversely impact the growth of both annual and perennial crops and may do so in both agricultural and forest ecosystems (28), with disease being incited at virtually any period of plant development. Disease symptoms range from damping-off to hypocotyl and coleoptile rot of young seedlings to root and crown rot of established plants.

Binucleate Rhizoctonia spp. may function as plant pathogens; however, the majority exhibit a saprophytic habit or, less commonly, develop a symbiotic association with plants (43). Although many species of binucleate Rhizoctonia have been described (9), the most commonly used system for classifying binucleate Rhizoctonia isolates is the one proposed by Sneh et al. (42), which classified binucleate Rhizoctonia isolates into AG-A through S. Although binucleate Rhizoctonia spp. occur worldwide, distribution of the various groups is poorly documented, with many groups appearing to be saprophytic, in- cluding AG-C, -H, -K, -L, -N, and -O (9). Diseases incited by pathogenic isolates include sharp eyespot of cereals and yellow patch of turf (Agrotis palustris Huds.), as well as damping-off and root rot of strawberry (Fragaria ananassa Duch.), sugar beet (Beta vulgaris L.), vegetables, and many other hosts (9).

In South Africa, Rhizoctonia spp. often have been isolated from barley (Hordeum vulgare $\mathrm{L}$.), canola (Brassica napus $\mathrm{L}$. var. oleifera DC), clover (Trifolium spp.), lucerne (Medicago sativa L.), lupin (Lupinus spp.), medic (annual Medicago spp.), and wheat (Triticum aestivum L.) (S. C. Lamprecht, E. E. Auret, and J. C. Janse van Rensburg, unpublished data). Rhizoctonia isolates have not been well characterized in South Africa, with only $R$. solani AG-6 and $R$. cerealis Van der Hoeven, which cause crater disease of wheat in summer rainfall regions of South Africa, being characterized to the species or AG level $(36,39)$. Rhizoctonia spp. are known to have a significant impact on stand establishment and yield of these crops in other countries $(4,14,17,19,25,33,35,47,48)$, suggesting that they have the potential to limit crop production within the rotation systems employed in South Africa. Therefore, characterization of Rhizoctonia spp. associated with barley, canola, clover, lucerne, lupin, medic, and wheat need further investigation.

The objectives of this study were to (i) determine the optimal developmental stage for isolating Rhizoctonia spp. associated with the seven rotation crops barley, canola, clover, lucerne, lupin, medic, and wheat; (ii) determine the distribution of Rhizoctonia spp. isolated from these crops among the known AGs; and (iii) assess the nature of the relationship between representatives of the various AGs and the different crop species.

\section{MATERIALS AND METHODS}

Field trial. Rhizoctonia spp. were isolated from a crop rotation trial over a 4year period (2000 to 2003) at the Tygerhoek experimental farm, Riviersonderend. The land used for the rotation trial previously was planted to lucerne for 4 years. The following crops were included in the trial: canola (cv. Varola 50), barley (cv. Clipper), alfalfa or lucerne (cv. SA Stan- 
dard), lupin (Lupinus angustifolius cv. Wonga), wheat (cv. SST57), and a mixture of medic (M. truncatula cvs. Mogul, Parabinga, and Sephi), and clover (Trifolium michelianum cv. Patrick). The trial site contained four different rotation systems, each consisting of four replicates. The four rotation systems included system one (barley and wheat), system two (barley, medicclover mixture, and wheat), system three (barley, canola, lupin, and wheat), and system four (lucerne monoculture). Sys-

Table 1. Rotation systems (four) and withinrotation system crop sequences $(n=10)$ used in this study

\begin{tabular}{lc}
$\begin{array}{l}\text { Rotation } \\
\text { system }\end{array}$ & $\begin{array}{c}\text { Crop sequence } \\
(\mathbf{2 0 0 0 - 2 0 0 1 - 2 0 0 2 - 2 0 0 3})^{\mathbf{z}}\end{array}$ \\
\hline 1 & W-B-W-B \\
& B-W-B-W \\
2 & M-W-M-B \\
& W-M-B-M \\
& B-M-W-M \\
& M-B-M-W \\
3 & L-W-C-B \\
& W-C-B-L \\
& C-B-L-W \\
& B-L-W-C \\
4 & Luc-Luc-Luc-Luc \\
\hline $\mathrm{z}$ W = wheat B = barley, M = medic-clover mix \\
L= lupin, C = canola, and Luc = lucerne.
\end{tabular}

Table 2. Rhizoctonia isolates used for conventional hyphal fusion reactions, in vitro temperature growth studies, and pathogenicity testing

\begin{tabular}{|c|c|c|}
\hline $\begin{array}{l}\text { Nuclear } \\
\text { status, } \text { AG }^{\mathbf{y}}\end{array}$ & $\begin{array}{c}\text { Accession } \\
\text { number }^{\mathrm{z}}\end{array}$ & Origin \\
\hline \multicolumn{3}{|l|}{ Multinucleate } \\
\hline \multirow[t]{3}{*}{ AG-2-1 } & PPRI 7426 & Lupin \\
\hline & PPRI 7427 & Canola \\
\hline & PPRI 7428 & Medic \\
\hline \multirow{2}{*}{ AG-2-2 } & PPRI 7429 & Medic \\
\hline & PPRI 7430 & Medic \\
\hline \multirow[t]{3}{*}{ AG-3 } & PPRI 7431 & Lupin \\
\hline & PPRI 7432 & Canola \\
\hline & PPRI 7433 & Wheat \\
\hline \multirow[t]{6}{*}{ AG-4 HG-II } & PPRI 7434 & Barley \\
\hline & PPRI 7435 & Wheat \\
\hline & PPRI 7436 & Medic \\
\hline & PPRI 7437 & Barley \\
\hline & PPRI 7438 & Wheat \\
\hline & PPRI 7439 & Medic \\
\hline \multirow[t]{2}{*}{ AG-11 } & PPRI 7440 & Lupin \\
\hline & PPRI 7441 & Lupin \\
\hline \multicolumn{3}{|l|}{ Binucleate } \\
\hline \multirow[t]{3}{*}{ AG-A } & PPRI 7414 & Lucerne \\
\hline & PPRI 7415 & Barley \\
\hline & PPRI 7416 & Medic \\
\hline \multirow[t]{3}{*}{ AG-I } & PPRI 7420 & Barley \\
\hline & PPRI 7421 & Lupin \\
\hline & PPRI 7422 & Wheat \\
\hline \multirow[t]{3}{*}{ AG-K } & PPRI 7423 & Lucerne \\
\hline & PPRI 7424 & Lupin \\
\hline & PPRI 7425 & Canola \\
\hline \multirow[t]{3}{*}{ Un. species } & PPRI 7417 & Wheat \\
\hline & PPRI 7418 & Wheat \\
\hline & PPRI 7419 & Wheat \\
\hline
\end{tabular}

y $\mathrm{AG}=$ anastomosis group and Un. species = unidentified Rhizoctonia spp.

${ }^{\mathrm{z}}$ Cultures deposited in the National Collection of Fungi at the ARC-Plant Protection Research Institute in Pretoria, South Africa. tems one, two, and three included 10 crop sequences over the 4 years (Table 1). Planting dates for all crops in the 4 years were either mid-April or early May, except for lucerne which, being a perennial crop, was planted only in 2000. The medicclover mixture also re-established itself in 2002 and 2003.

Sampling and isolation. Plants were collected at three sampling times in 2000 , 2001, and 2003 (i.e., at the seedling [4 to 6 weeks after planting], midseason [12 to 14 weeks after planting], and flowering or seedpod [20 to 22 weeks after planting] stages). In 2002, plants were sampled only at the flowering or seedpod stages. In all, 60 plants were collected from 10 sampling locations (6 plants/location) along a zigzag ("W") pattern through each experimental plot at each sampling time. This study was an attempt to survey the diversity of Rhizoctonia spp. associated with this cropping system; therefore, plant symptoms were not used as a factor in selecting samples. Plants were washed under running tap water to remove adhering soil and rinsed twice in sterile distilled water. Small pieces of root and hypocotyl, coleoptile, or crown tissue with lesions were excised and plated onto the following growth media: water agar (WA) (Agar Bacteriological, Biolab Diagnostics, Midrand, South Africa), WA amended with novostreptomycin at $200 \mu \mathrm{g} \mathrm{ml}^{-1}$, and potato dextrose agar (PDA) (Biolab Diagnostics) amended with novostreptomycin at $200 \mu \mathrm{g} \mathrm{ml}^{-1}$. In all, 18 hypocotyl, coleoptile, or crown and 18 root pieces were plated for each experimental plot at each sampling time for each crop. The total number of pieces plated for each crop at each sampling time was 864,288 , $144,288,516$, and 864 for barley, canola, lucerne, lupin, medic-clover mixture, and wheat, respectively. The total number of pieces plated per crop depended upon the number of plots containing the specific crops within the rotation trial.

The rotation system experiment was a randomized complete block design structure with 20 main plots (treatments) randomly replicated within four blocks. The 20 main plots (rotation systems one, two, and three) consisted of a 10-by-2 factorial (10 crop sequences $\times$ two tillage practices) with three rotation systems. Three sampling times per year were used as a subplot factor, which can be referred to as a random split-plot in time (24). A further subsubplot was the Rhizoctonia groups (binucleate and multinucleate) isolated from the plant samples.

Nuclear staining. The nuclear status of multiple cells of more than one hyphae of all Rhizoctonia spp. isolates was determined by staining using a fluorocrome, acridine orange stain followed by fluorescence microscope imaging (51). The nuclei of 20 cells per isolate were counted in order to determine the nuclear status of each isolate.
AG typing through sequence analyses of the rDNA internal transcribed spacer (ITS) regions. Mycelia of Rhizoctonia cultures that were grown on PDA plates at $25^{\circ} \mathrm{C}$ with a 12 -h photoperiod for 5 days were used for DNA extractions. DNA was extracted from mycelia according to the protocol of Lee and Taylor (22).

Polymerase chain reaction (PCR) amplification of Rhizoctonia DNA was conducted using the primer set internal transcribed spacer (ITS) $4 \quad\left(5^{\prime}\right.$-TCCTCC GCTTATTGATATGC-3')/ITS5 (5'-GGA AGTAAAAGTCGTAACAAGG-3') (49). Reactions were carried out in a volume of $50 \mu \mathrm{l}$ that included $1 \mu \mathrm{l}$ of diluted DNA (5 to $10 \mathrm{ng}$ ), 2.5 units of Amplitaq Gold DNA polymerase, $1 \times$ manufacturer's reaction buffer, $3 \mu \mathrm{l}$ of a $25-\mathrm{mM} \mathrm{MgCl}_{2}$ solution, and $200 \mu \mathrm{M}$ each dNTP. Amplification reactions were conducted in a GeneAmp 9700 thermal cycler (Applied Biosystems, Foster City, CA) using reaction conditions of initial denaturation at $94^{\circ} \mathrm{C}$ for $2 \mathrm{~min}$, followed by 40 cycles of $94^{\circ} \mathrm{C}$ for $60 \mathrm{~s}$, $50^{\circ} \mathrm{C}$ for $45 \mathrm{~s}$, and $72^{\circ} \mathrm{C}$ for $60 \mathrm{~s}$, with a final extension step at $72^{\circ} \mathrm{C}$ for $7 \mathrm{~min}$.

The resulting amplification products were cloned into the vector pCR 4-TOPO (Invitrogen, Carlsbad, CA) according to the manufacturer's instructions. The cloning reaction $(2 \mu \mathrm{l})$ was used to transform chemically competent Escherichia coli TOP10 cells according to the manufacturer's instructions (Invitrogen). Plasmid DNA was isolated from transformed colonies using the S.N.A.P. miniprep plasmid purification kit (Invitrogen). Plasmid DNA containing the appropriate-sized amplification product insert was identified through EcoRI restriction digestion and subsequently utilized in DNA sequence reactions.

Sequencing reactions were conducted using the CEQ DTCS Quick Start Kit (Beckman Coulter, Fullerton, CA). Reactions were performed in a total volume of $20 \mu \mathrm{l}$ containing $2 \mu \mathrm{l}$ of plasmid DNA (10 to $20 \mathrm{ng}$ ), $2 \mu \mathrm{l}$ of M13 reverse primer (1.78 $\left.\mathrm{pMol} \mu \mathrm{l}^{-1}\right), 4.0 \mu \mathrm{l}$ of manufactured Master Mix, and $12 \mu \mathrm{l}$ of $\mathrm{dH}_{2} \mathrm{O}$, with an initial denaturation at $96^{\circ} \mathrm{C}$ for $60 \mathrm{~s}$ followed by 30 cycles of $96^{\circ} \mathrm{C}$ for $20 \mathrm{~s}, 50^{\circ} \mathrm{C}$ for $20 \mathrm{~s}$, and $60^{\circ} \mathrm{C}$ for $20 \mathrm{~s}$. Upon completion of the sequencing reaction, stop solution $(2 \mu \mathrm{l}$ of $3 \mathrm{M} \mathrm{NaOAc}, \mathrm{pH} \mathrm{5.2}$, and $2 \mu \mathrm{l}$ of $100 \mathrm{mM}$ EDTA, pH 8.0) and $1 \mu$ lof glycogen was added prior to ethanol precipitation of DNA. Samples were resuspended in $40 \mu \mathrm{l}$ of sample loading solution and analyzed using a CEQ 8000 Genetic Analysis system. For each resulting sequence, a BLAST search was performed on GenBank to identify the most closely related species.

AG typing using conventional hyphal fusion reactions. The AG of 28 representative isolates was confirmed by conventional hyphal anastomosis testing (Table $2)$. These isolates, which also were charac- 
terized through sequence analyses of the rDNA-ITS region, were paired with known tester strains (Table 3 ) on $2 \%$ WA in petri dishes. The cultures were incubated under cool white light with a 12-h photoperiod at $25^{\circ} \mathrm{C}$. Analysis of hyphal fusion was conducted by examining the zone of hyphal interaction at $\times 40$ magnification using a light microscope.

Temperature growth studies. The effect of temperature on in vitro radial growth of 28 Rhizoctonia isolates, representing nine AGs (Table 2), was studied at seven different temperatures $(5,10,15,20$, 25,30 , and $\left.35^{\circ} \mathrm{C}\right)$. Mycelial plugs $(0.6 \mathrm{~cm}$ in diameter) were transferred from the edge of 5-day-old actively growing colonies to PDA. Cultures were incubated in the dark and colony radius was measured in four directions for each PDA plate after $48 \mathrm{~h}$. Each isolate was replicated three times at each temperature.

Pathogenicity trials. Three independent trials were conducted. The first trial determined the optimal inoculum concentration based on seedling emergence. The second trial tested pathogenicity and relative virulence of the nine different AGs based on seedling emergence of the seven rotation crops. The third trial tested pathogenicity and relative virulence of all AGs based on rot development on 14-day-old seedlings of the seven rotation crops.

Pathogenicity trials were conducted using plastic pots $13 \mathrm{~cm}$ in diameter with a holding capacity of $700 \mathrm{~g}$ of planting medium. The planting medium was made up of equal quantities of soil, perlite, and sand, which was pasteurized $(30 \mathrm{~min}$ at $83^{\circ} \mathrm{C}$ ) for 3 days before being mixed with inoculum (inoculum concentration and emerging seedling trial) or sown with seed (14-day-old seedling trial). All trials were conducted in a growth chamber employing a $15^{\circ} \mathrm{C}$ night and $25^{\circ} \mathrm{C}$ day temperature regime, $10-\mathrm{h}$ photoperiod, and relative humidity of 60 to $70 \%$. Pots were watered every third day to field capacity.

To establish an appropriate inoculum concentration for use in subsequent trials, canola and wheat were inoculated with AG-2-1 (PPRI 7426), AG-4 HG-II (PPRI 7434), and AG-K (PPRI 7423) at five inoculum concentrations $(0.005,0.0158$, $0.05,0.158$, and $0.5 \%$ mass inoculum $/$ mass planting media [wt/wt]) 1 day prior to planting seed. Inoculum was prepared on millet seed as previously described by Strauss and Labuschagne (44). Controls consisted of noninoculated millet seed at the five different concentrations. Pathogenicity and relative virulence of each isolate at different inoculum concentrations were determined by calculating the percent damping-off and percent reduction in dry mass of seedlings 14 days after planting. Percent damping-off caused by each $\mathrm{AG}$ on a specific crop was determined by using the following formula: ([number of emerged seedlings in control crop A - number of emerged seedlings in AGinoculated crop A]/number of emerged seedlings in control crop A) $\times 100$. The percent dry mass reduction was determined using a similar formula, except that dry mass was used instead of number of emerged seedlings. The experiment used a randomized complete block design structure. The treatment design for the trial was a 3-by-2-by-5 factorial (three AGs, two crops, and five concentrations). An experimental unit consisted of a pot with 50 seed. The trial was conducted twice, with three replicates per treatment.

The capacity of 28 Rhizoctonia spp. isolates representing nine AGs (Table 2) to reduce plant emergence and biomass of seven rotation crops, including canola (cv. Varola 50), clover (cv. Patrick), lucerne (cv. SA Standard), lupin (cv. Wonga), medic (cv. Sephi), wheat (cv. SST57), and barley (cv. Clipper), was determined. Inoculation of planting media was conducted one inoculum concentration $(0.05 \%$, wt/wt) was used. Pathogenicity and relative virulence were determined as described above. The experimental design was a randomized block design. The treatment design was a 29-by-7 factorial (28 isolates representing nine AGs and a control, and seven crops) with two replications per treatment. An experimental unit consisted of a pot with 50 seed for all the crops except lupin, where 20 seed were planted in each pot. The trial was conducted twice.

The 28 Rhizoctonia spp. isolates (Table 2) also were evaluated for their ability to cause rot (root, hypocotyl, or coleoptile) of 14-day-old seedlings. Pots were filled with pasteurized planting medium and an empty test tube ( 17 by $150 \mathrm{~mm}$ ) was inserted in the center of each pot. Five planting holes were made around each test tube at $1 \mathrm{~cm}$ from the test tube. The same seven crop cultivars used in the emerging seedling pathogenicity trial also were used in the 14-day-old pathogenicity trial. At 14 days as in the concentration trial, except that

after planting, the test tube was removed from each pot and planting medium amended with $0.5 \%(\mathrm{wt} / \mathrm{wt})$ inoculum was placed in the holes left by the test tube. Root rot was rated according to MacNish et al. (27) on a 0 -to- 4 scale, where $0=$ no obvious symptoms, $1=$ slight discoloration or small superficial lesions, $2=$ moderate discoloration or extensive but nongirdling lesions, 3 = extensive discoloration of tissue or girdling lesions, and $4=$ plant dead. Coleoptile (barley and wheat) and hypocotyl (canola, clover, lupin, lucerne, and medic) rot also were rated on a 0 -to-4 scale as described for root rot. The experimental and treatment design for the trial was the same as for the emerging seedling trial (a 29-by-7 factorial with two replications [pots] per treatment). An experimental unit consisted of a pot with 25 seed for each crop except for lupin, in which 15 seed were planted in each pot. The trial was conducted twice and utilized a randomized block design.

Statistical analysis. For the rotation system, analysis each year was done separately because crop sequences differed from one year to the next. Although isolations were done separately from hypocotyls, coleoptiles, crowns, and roots, these data were combined for the analysis of variance. Analysis of variance was performed for each separate year using SAS (version 8; SAS Institute, Inc., SAS Campus Drive, Cary, NC) and the student's $t$ test and least significant difference (LSD) were calculated to compare means of significant effects at the $5 \%$ significance level.

For the temperature growth studies, second-order polynomials were fitted on the radial length over temperature for each isolate by $\mathrm{AG}$ combination and replicates (41). The optimum growth temperature and area under each curve were calculated. These measurements were subjected to analysis of variance and the means were compared using student's $t$ test and LSD at the $5 \%$ significance level.

Table 3. Rhizoctonia isolates used as reference isolates for conventional hyphal fusion studies ${ }^{\mathrm{z}}$

\begin{tabular}{lll}
\hline Rhizoctonia group, AG & \multicolumn{1}{c}{ Isolate } & \multicolumn{1}{c}{ Collector or supplier } \\
\hline Multinucleate & & Mazzola, M. \\
AG-2-1 & H-24 & Mazzola, M. \\
AG-2-2 & $455-11$ & PPR/Ogoshi 1988 \\
AG-3 & PPRI 2152 (W14L) & Mazzola, M. \\
AG-4 & 6-3-6 215 (F 10) & PPRI/Ogoshi 1988 \\
& PPRI 2153 & Mazzola, M. \\
AG-4 HG-II & RH 165 & Barbetti, M. \\
AG-11 & WAC9938 & Barbetti, M. \\
& WAC10000 & Barbetti, M. \\
Binucleate & WAC10001 & \\
AG-A & & PPRI/Ogoshi 1993 \\
AG-D & PPRI 2130 (C-517) & PPRI/Ogoshi 1993 \\
& PPRI 2135 (OR706) & Mazzola, M. \\
AG-I & C-610 & Mazzola, M. \\
AG-K & AV-2 & PPRI/Ogoshi 1993
\end{tabular}

${ }^{\mathrm{z}} \mathrm{AG}=$ anastomosis group and PPRI $=$ Plant Protection Research Institute (Agricultural Research Council). 
Statistical analyses of data were conducted similarly for all three pathogenicity trials. Levene's variance ratio test (23) was performed to test for homogeneity of trial variances between the trial repeats. In these analyses, data of the two independent trials were considered block treatments and the replications within each trial were used as subsamples, providing that Levene's variance ratio test showed homogeneity in trial variance. Data were subjected to analysis of variance using SAS (version 8; SAS Institute, Inc.), and the Shapiro-Wilk test was performed to test for normality (37). In cases where deviations from normality were due to kurtosis and not skewness, the data were accepted as reliable and the results were interpreted without transformation (10). Pearson correlations between variables also were calculated.

\section{RESULTS}

Sampling and isolation. In all, 428 Rhizoctonia spp. isolates were obtained during the 4 years of the crop rotation trial. Nuclear staining of the isolates revealed the presence of $104(24 \%)$ multinucleate (R. solani) and $324(76 \%)$ binucleate Rhizoctonia isolates. The highest number of multinucleate isolates were isolated from medic-clover (37 isolates), followed by canola and wheat (20 isolates each), barley (17 isolates), lupin (10 isolates), and lucerne ( 0 isolates). The highest number of binucleate isolates were isolated from medic-clover (132 isolates), followed by canola (53 isolates), wheat (50 isolates), barley and lucerne (31 isolates each), and lupin (27 isolates). Significantly $(P \leq 0.05)$ higher recovery of binucleate compared with multinucleate isolates was obtained for all 4 years (Table 4 ). In all 4 years, the recovery frequency of the two Rhizoctonia groups differed significantly $(P=0.0105$ [2000], $P=0.0464$ [2001], $P=0.0060$ [2002], and $P=0.0062$ [2003]). Due to the relatively low number of isolates obtained in each year within the four different rotation systems, statistical analyses could not be conducted to evaluate whether different rotation systems affected the incidence of Rhizoctonia spp. on the different crops.

Sampling time significantly $(P \leq 0.05)$ affected the frequency of isolation of Rhizoctonia groups in $2000(P=0.0003)$ and in $2001(P=0.0037)$, but not in 2003 $(P=0.1104)$. In 2000, 2001, and 2003, recovery of Rhizoctonia spp. was higher during the flowering or seedpod stage than during the seedling or midseason stages (Table 5).

AG typing through sequence analyses of the rDNA ITS regions. Based upon sequence analysis, the population (324 isolates) of multinucleate $R$. solani contained isolates belonging to AG-4 HG-II (69\%), AG-2-1 (19\%), AG-3 (8\%), AG-2-2 (2\%), and AG-11 (2\%). The population (104 isolates) of binucleate Rhizoctonia spp. included isolates belonging to AG-K $(53 \%)$, AG-A (10\%), AG-I (5\%), and unidentified groups $(32 \%)$. A large number of binucleate isolates (unidentified group) did not exhibit a clear genetic affinity with any binucleate Rhizoctonia spp. according to the ITS sequences contained in the GenBank library. Among the multinucleate Rhizoctonia groups, AG-2-1 was isolated from canola, lupin, medic, and wheat; AG3 from canola, lupin, and wheat; and AG-4 HG-II from barley, canola, lupin, medic, and wheat. However, AG-2-2 and AG-11 were isolated only from medic and lupin,

Table 4. Mean percent recovery of bi- and multinucleate Rhizoctonia groups from crop rotations over a 4-year period

\begin{tabular}{|c|c|c|c|c|}
\hline \multirow[b]{2}{*}{ Rhizoctonia group } & \multicolumn{4}{|c|}{ Recovery $(\%)^{y}$} \\
\hline & 2000 & 2001 & 2002 & 2003 \\
\hline Binucleate & $1.19 \mathrm{a}$ & $0.80 \mathrm{a}$ & $1.42 \mathrm{a}$ & $0.91 \mathrm{a}$ \\
\hline Multinucleate & $0.42 \mathrm{~b}$ & $0.38 \mathrm{~b}$ & $0.35 \mathrm{~b}$ & $0.23 \mathrm{~b}$ \\
\hline$P$ value & 0.0105 & 0.0464 & 0.0060 & 0.0062 \\
\hline $\operatorname{LSD}(P=0.05)^{\mathrm{z}}$ & 0.544 & 0.408 & 0.490 & 0.435 \\
\hline
\end{tabular}

${ }^{y}$ Means within a year (in a column) followed by the same letter do not differ significantly $(P=0.05)$.

${ }^{\mathrm{z}} \mathrm{LSD}=$ least significant difference.

Table 5. Effect of sampling time on the mean percent recovery of Rhizoctonia isolates from crop rotations over a 4-year period

\begin{tabular}{lcccc}
\hline & \multicolumn{4}{c}{${\text { Recovery }(\boldsymbol{\%})^{\mathbf{y}}}$} \\
\cline { 2 - 5 } Sampling time $^{\mathbf{z}}$ & $\mathbf{2 0 0 0}$ & $\mathbf{2 0 0 1}$ & $\mathbf{2 0 0 2}$ & $\mathbf{2 0 0 3}$ \\
\hline 1 & $0.42 \mathrm{~b}$ & $0.05 \mathrm{~b}$ & $\ldots$ & $0.35 \mathrm{a}$ \\
2 & $0.17 \mathrm{~b}$ & $0.40 \mathrm{~b}$ & $\ldots$ & $0.42 \mathrm{a}$ \\
3 & $1.81 \mathrm{a}$ & $1.32 \mathrm{a}$ & 0.89 & $0.96 \mathrm{a}$ \\
$P$ value & 0.0003 & 0.0037 & $\ldots$ & 0.1104 \\
LSD $(P=0.05)$ & 0.482 & 0.559 & $\ldots$ & 0.638
\end{tabular}

${ }^{\mathrm{y}}$ Means within a year (in a column) followed by the same letter do not differ significantly $(P=0.05)$; $\ldots=$ plants sampled only at third sampling time in 2002.

${ }^{\mathrm{z}}$ Sampling time: $1=$ seedling stage ( 4 to 6 weeks after planting), $2=$ midseason ( 12 to 14 weeks after planting), and $3=$ flowering stage ( 20 to 22 weeks after planting); $L S D=$ least significant difference. respectively. Binucleate Rhizoctonia AG-A was isolated from all the crops in the study, except from lupin; AG-I was isolated from barley, canola, lupin, and wheat and AG-K and the unidentified binucleate group were isolated from all the crops in the study.

AG typing using conventional hyphal fusion reactions. All $R$. solani isolates were anastomosed successfully with the respective tester isolates and all exhibited a $\mathrm{C} 2$ reaction as described by Carling (5). The multinucleate Rhizoctonia isolates that were identified in this manner included AG-2-1 (three isolates), AG-2-2 (two isolates), AG-3 (three isolates), AG-4 HG-II (six isolates), and AG-11 (two isolates). AG-I (three isolates) and AG-K (three isolates) were the only binucleate AGs that were anastomosed successfully with the tester isolates. The unidentified binucleate Rhizoctonia group failed to anastomose with tester isolates of AG-A, AG-I, AG-D, and AG-K. The AG group of isolates as determined through conventional anastomosis typing corresponded with the identification determined through sequence analyses of the ITS region. The only exception was three AG-A isolates that did not anastomose with the tester AG-A isolate PPRI 2130 (C-517).

Temperature growth studies. Significant differences in the temperature for optimum growth as well as growth rate at different temperatures (area under the curve) was observed among and within the nine AGs (Table 6). Rhizoctonia AG-2-2, AG-4 HG-II, and AG-K had significantly $(P \leq 0.05)$ higher optimum growth temperatures than the other AGs (Table 6).

Pathogenicity trials. In all the pathogenicity tests, variance for the data from the two independent trials was comparable based on Levene's variance ratio test (23). Consequently, data from repeat trials were combined in all the analyses. In both the inoculum concentration and emerging seedling pathogenicity trials, correlation analyses showed that there was a very high correlation $(P<0.0001)$ between percent damping-off and percent dry mass reduction. Therefore, only percent damping-off subsequently will be discussed as a measure of pathogenicity and virulence.

In the inoculum concentration trial, the multinucleate $R$. solani isolates (AG-2-1 and AG-4 HG-II) were more virulent on canola than on wheat. Therefore, at high inoculum concentrations $(0.158$ and $0.5 \%$, $\mathrm{wt} / \mathrm{wt}$ ), significant differences in the extent of damping-off of canola caused by AG-21 and AG-4 HG-II could not be distinguished (Fig. 1). In contrast, on wheat, significant $(P \leq 0.05)$ differences in percent damping-off between the multinucleate isolates could be discerned at all inoculum concentrations, except at the lowest inoculum concentration (0.005\%; Fig. 1). Binucleate Rhizoctonia AG-K caused low percentages of damping-off of canola as 
well as wheat at all inoculum concentrations (Fig. 1).

In the emerging seedling trial, significant crop-AG interactions were recorded for both damping-off $(P<0.0001)$ and dry mass reduction $(P<0.0001)$. There were no significant differences in percent damping-off $(P>0.05)$ or percent dry mass reduction $(P>0.05)$ caused by different isolates within seven of the nine AGs. However, a significant difference was present in percent damping-off $(P<0.0001)$ and percent dry mass reduction $(P<$ $0.0001)$ caused by isolates within AG-2-1 and $\mathrm{AG}-2-2$.

Pathogenicity and relative virulence of the $R$. solani AGs varied toward seedlings of the seven test crops. $R$. solani AG-2-1 caused significant damping-off of canola, lucerne, lupin, and medic, with canola and lupin being the most susceptible. Barley, clover, and wheat were not susceptible to AG-2-1 (Table 7). $R$. solani AG-2-2 caused significant damping-off (between 22 and $88 \%$ ) on all seven crops (Table 7). Inoculation of the seven crops with AG-2-2 resulted in significantly more damping-off in canola, lupin, and medic (more than 87\%) than the other crops. Clover and lucerne had the least amount $(<25 \%)$ of dampingoff when inoculated with AG-2-2 (Table 7). Similar to AG-2-2, R. solani AG-4-HGII also was capable of causing significant damping-off on all seven crops. $R$. solani AG-4-HG-II was significantly less virulent on barley and wheat than on the other five rotation crops. $R$. solani AG-3 was least virulent of all the multinucleate AGs on all seven crops, causing significant dampingoff only on canola, lupin, and medic (Table $7)$. $R$. solani AG-11 was moderately virulent on canola, clover, lucerne, lupin, and medic, not causing more than $50 \%$ damping-off (Table 7).

The binucleate Rhizoctonia isolates did not cause significant damping-off on most of the crops (Table 7). Rhizoctonia AG-I and AG-A caused significant damping-off only on lupin (7.92\%) and canola (8.29\%), respectively. Rhizoctonia AG-K caused a significant amount of damping-off (between 12 and $22 \%$ ) on canola, lupin, clover, and medic (Table 7).

The number of Rhizoctonia AGs capable of inciting disease on any specific crop plant varied among those evaluated in this study (Table 7). Barley and wheat were least susceptible, suffering significant damping-off only when inoculated with two AGs (AG-2-2 and AG-4 HG-II). Clover and lucerne were susceptible to four AGs (AG-2-2, AG-4 HG-II, AG-11, and AG-K), showing between 8 and $84 \%$ damping-off. Medic was susceptible to six AGs, with more than $22 \%$ damping-off caused by all AGs. Lupin and canola were susceptible to six of the AGs (Table 7).

In the 14-day-old seedlings trial, significant crop-AG interactions were recorded for $\operatorname{root}(P<0.0001)$, coleoptile $(P=$
$0.0228)$, and hypocotyl $(P<0.0001)$ rot. Significant differences in root rot severity caused by isolates within AG-4 HG-II ( $P=$ $0.0010)$ and AG-K $(P=0.0125)$ and for coleoptile rot caused by isolates within AG-4 HG-II $(P=0.0398)$ were observed.

In the 14-day-old seedling inoculation experiments, pathogenicity and relative virulence of $R$. solani AGs differed among the seven rotation crops examined. $R$. solani AG-2-1 caused the highest amount of root rot on 14-day-old canola and lupin seedlings, whereas medic and canola seedlings had the highest hypocotyl rot rating when inoculated with this AG. $R$. solani AG-2-1 was only weakly virulent or not pathogenic to barley, clover, lucerne, and wheat (Table 7). R. solani AG-2-2 caused significant rot (root, hypocotyl, or coleoptile) on 14-day-old inoculated seedlings of all test crops except clover (Table 7). Lupin and medic were most susceptible to AG-2-2, having significantly more root and hypocotyl or coleoptile rot than lu- cerne, barley, and wheat (Table 7). R. solani AG-3 caused significant root rot on canola and lupin, as well as slight but significant hypocotyl rot on 14-day-old inoculated medic seedlings (Table 7). $R$. solani AG-4 HG-II caused significant disease (either root, hypocotyl, or coleoptile rot) on 14-day-old seedlings of all the rotation crops, although it was only weakly virulent on barley and wheat (Table 7). $R$. solani AG-11 was mildly virulent and caused significant root rot on all crops except barley and wheat (Table 7).

Isolates of binucleate Rhizoctonia spp. did not cause significant aboveground disease symptoms (coleoptile or hypocotyl rot) on 14-day-inoculated seedlings of any of the crops except for AG-K, which caused significant hypocotyl rot on medic (Table 7). Rhizoctonia AG-K also caused significant root rot on 14-day-old canola, lucerne, lupin, and medic seedlings (Table 7). None of the other binucleate Rhizoctonia spp. isolates caused

Table 6. Comparison of temperatures at optimum radial growth and total growth area under the curve (growth rate) for the nine anastomosis groups (AGs) of Rhizoctonia following a temperature growth study at seven different temperatures ${ }^{x}$

\begin{tabular}{lcc}
\hline AG $^{\mathbf{y}}$ & Optimum temperature $^{\mathbf{z}}$ & Area under the curve $^{-}$ \\
\hline AG-2-1 & $21.65 \mathrm{~d}$ & $492.18 \mathrm{e}$ \\
AG-2-2 & $25.90 \mathrm{a}$ & $549.88 \mathrm{c}$ \\
AG-3 & $21.72 \mathrm{~d}$ & $521.08 \mathrm{~d}$ \\
AG-4 HG-II & $22.43 \mathrm{c}$ & $637.95 \mathrm{a}$ \\
AG-11 & $21.63 \mathrm{~d}$ & $572.87 \mathrm{~b}$ \\
AG-A & $20.97 \mathrm{e}$ & $419.61 \mathrm{~g}$ \\
AG-I & $20.70 \mathrm{e}$ & $296.91 \mathrm{i}$ \\
AG-K & $23.21 \mathrm{~b}$ & $464.38 \mathrm{f}$ \\
UNBR & $21.04 \mathrm{e}$ & $318.37 \mathrm{~h}$ \\
$P$ value & $<0.0001$ & $<0.0001$ \\
LSD $(P=0.05)$ & 0.350 & 10.286 \\
\hline
\end{tabular}

x Values followed by the same letter in a column do not differ significantly $(P=0.05)$.

y $\mathrm{UNBR}=$ unidentified binucleate Rhizoctonia spp. and LSD = least significant difference.

z Temperature at optimum growth.

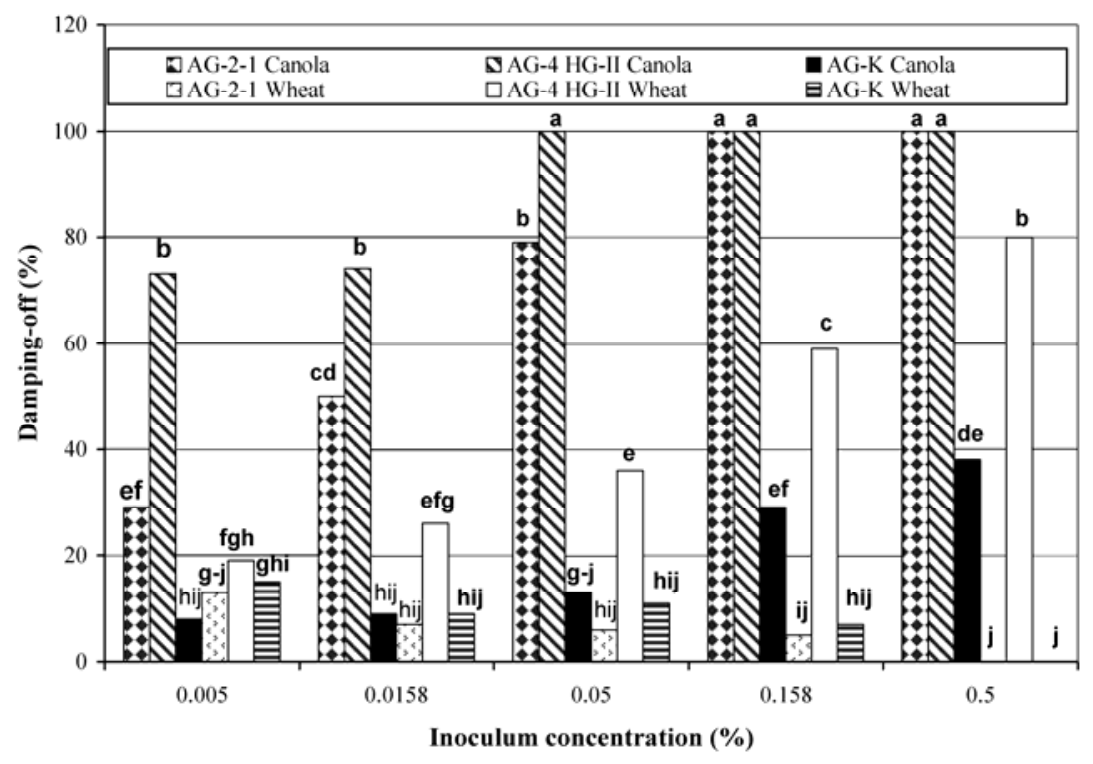

Fig. 1. Influence of inoculum concentration on percent damping-off of emerging canola and wheat seedlings caused by different anastomosis groups (AGs) of Rhizoctonia spp. Values are the mean percent damping-off of two replications and data are pooled over two experiments. 
significant root rot on any of the test crops (Table 7).

\section{DISCUSSION}

This study characterized Rhizoctonia populations associated with crop species (barley, canola, lucerne, lupin, medicclover, and wheat) that were grown within a 4-year crop rotational trial in the Western Cape province of South Africa. A significantly higher frequency of binucleate Rhizoctonia isolates, which are generally less virulent than multinucleate isolates (42), were present within the crop rotation trial. Similarly, in Australia, binucleate isolates were isolated at a higher frequency from lupin and cereal seedlings $(25,45)$. Contrarily, a number of researchers isolated higher numbers of multinucleate than binucleate Rhizoctonia spp. from barley, canola, and wheat in various regions of the world $(14,31,52)$. The higher numbers of binucleate Rhizoctonia spp. recovered in this study could be due to the lack of sur- face sterilization of plant materials prior to conducting isolations, thus favoring recovery of bi- versus multinucleate isolates. However, this seems unlikely because various investigations following the same procedure obtained a greater number of multi- than binucleate isolates $(25,31,45)$. A more likely explanation for the high incidence of binucleate isolates would be the continuous lucerne cropping history of the study site, which had been established since 1996. Various studies have documented that prolonged crop monoculture can induce Rhizoctonia spp.-suppressive soils $(29,43)$. Future research should be aimed at determining whether a higher incidence of nonpathogenic binucleate Rhizoctonia spp. is associated with disease suppression.

Rhizoctonia spp. were more frequently isolated from plants at the flowering or seedpod stage than at the seedling stage. A factor contributing to this trend could have been the more favorable temperatures $(20$ to $25^{\circ} \mathrm{C}$ ) for growth of the Rhizoctonia AGs during September and October (flowering or seedpod stage) compared with less favorable temperatures (below $20^{\circ} \mathrm{C}$ ) in July and August (midseason). Although isolates from all AGs tested exhibited in vitro growth at a wide range of temperatures (ranging from 15 to $30^{\circ} \mathrm{C}$ ), virulence was clearly evident at temperatures ranging from 20 to $25^{\circ} \mathrm{C}$ in plant assays. In Western Australia, an increase in recovery of Rhizoctonia isolates also was obtained from July to August (25).

The identification of Rhizoctonia AGs through sequence analyses allowed the typing of a large number of isolates (428 isolates). Sequence analyses identified five multinucleate Rhizoctonia AGs (AG-2-1, AG-2-2, AG-3, AG-4 HG-II, and AG-11) and three binucleate Rhizoctonia AGs (AG-A, AG-I, and AG-K). One limitation to sequence identification of Rhizoctonia AGs is that relatively little sequence data are available for isolates from the binucle-

Table 7. Mean percent damping-off of emerging seedlings, and root, coleoptile, and hypocotyl rot index of 14-day-old seedlings caused by different Rhizoctonia anastomosis groups (AGs) in artificially inoculated steam pasteurized soilv

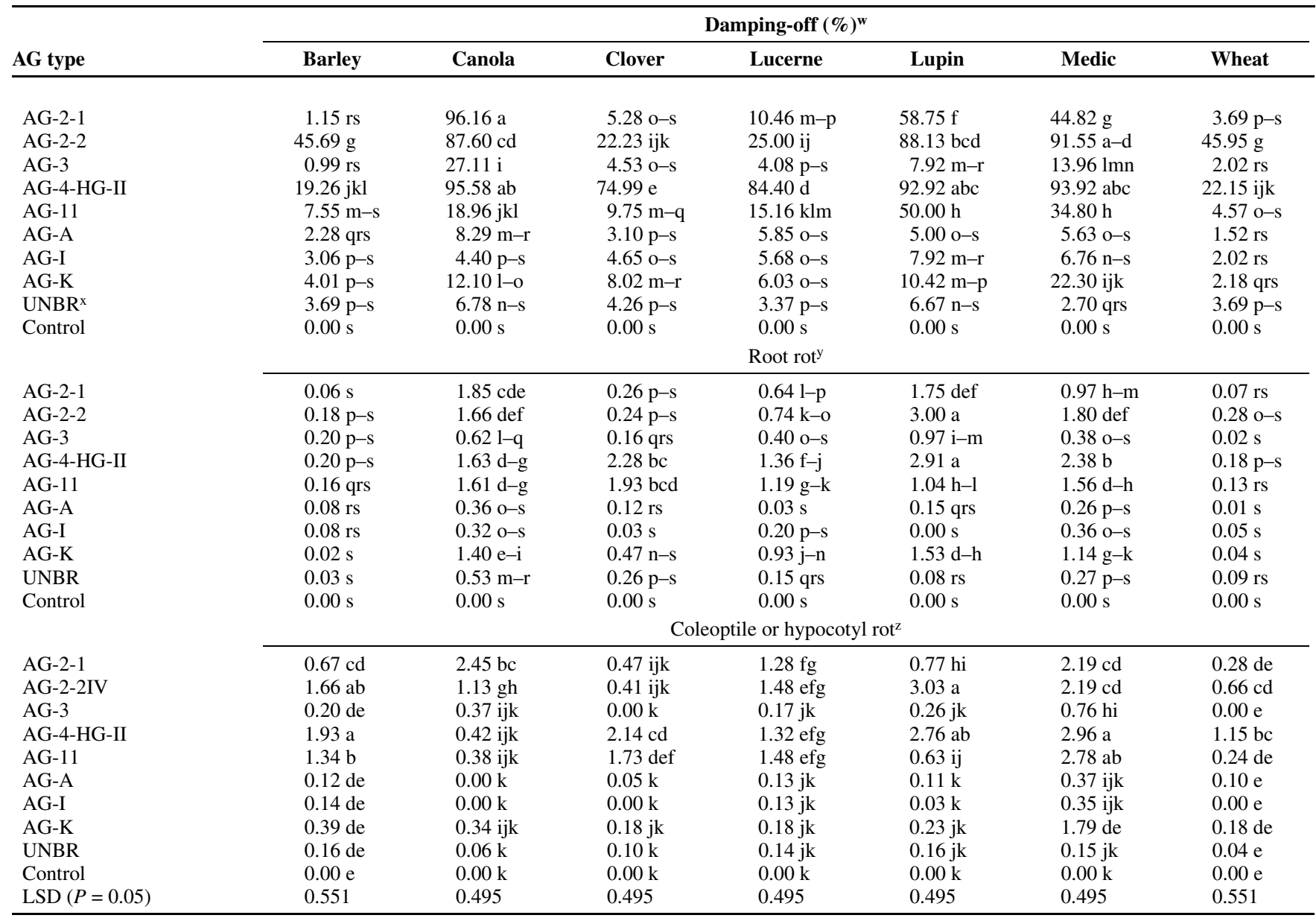

$\mathrm{v}$ Values are the mean percent damping-off, root, coleoptile, and hypocotyl rot (lesion) of two replications. Data are pooled over two experiments. Values followed by the same letter do not differ significantly $(P=0.05)$.

${ }^{\mathrm{w}} P$ value $<0.0001$ and least significant difference $(\mathrm{LSD} ; P=0.05)=7.638$

${ }^{\mathrm{x}} \mathrm{UNBR}=$ unidentified binucleate Rhizoctonia spp.

y The value index for rot was a 0 -to- 4 scale, where $0=$ no obvious symptoms, $1=$ slight discoloration or small superficial lesions, $2=$ moderate discoloration or extensive but nongirdling lesions, $3=$ extensive discoloration of tissue or girdling lesions, and $4=$ plant dead. $P$ value $<0.0001$ and LSD $(P=0.05)=0.468$.

${ }^{\mathrm{z}}$ Coleoptile rot was assessed for barley and wheat, and hypocotyl rot for canola, clover, lupin, lucerne, and medic, on a 0 -to- 4 scale as described above. $P$ value $=0.0228$ (coleoptile) and $<0.0001$ (hypocotyl) . 
ate groups. As a result, a subset (32\%) of the binucleate isolates from this study remained unidentified. The accuracy of our sequence identification was assessed through conventional hyphal anastomosis reaction studies on a subset of isolates. These analyses confirmed most identifications based upon ITS sequence data, with the exception of the AG-A isolates that did not exhibit anastomosis with the reference isolate. However, this result is inconclusive because only one reference isolate of AGA was available. Further investigations using additional AG-A reference isolates are required to clarify this finding.

In general, binucleate Rhizoctonia isolates were either nonpathogenic or weakly virulent, even though they were associated with most crops. This suggests that binucleate isolates were not important pathogens within the crop rotation trial. However, it is noteworthy that, in this study as well as others $(18,20,25)$, binucleate isolates sometimes can be pathogenic, especially those within AG-K. In our study, isolates of AG-K caused significant damping-off or rot on 14-day-old canola, lucerne, lupin, and medic seedlings. Similarly, AG-K was reported as moderately or weakly virulent toward canola (18). The binucleate AG-A and AG-I were able to cause only minor, though statistically significant, rates of damping-off of emerging canola and lupin seedlings. This significant damping-off caused by these AGs is difficult to interpret. It can be hypothesized that these isolates will most likely not be pathogenic in natural soil ecosystems where inoculum concentrations may be lower than that evaluated in this study. This is supported by the inoculum concentration trial data that showed a significant increase in percent damping-off caused by a binucleate isolate (AG-K) with increasing inoculum concentration on a more susceptible crop such as canola. Another factor that will influence the pathogenicity of AG-I and AG-A in natural soil ecosystems is interaction with a competitive soil microflora that can significantly reduce the capacity of Rhizoctonia isolates to incite disease as well as suppressing population levels $(30,38)$.

The $R$. solani AGs that are most likely to play an important role in yield reduction of rotations crops used in the Western Cape province include AG-2-1, AG-2-2, and AG-4-HG-II, because they were most virulent on specific rotation crops. $R$. solani AG-2-1 was highly virulent on canola seedlings, similar to other parts of the world where it is limiting canola production $(11,12,14,18)$. This AG also was pathogenic on lupin and medic but has not been reported pathogenic on these crops elsewhere, except for one report of its pathogenicity toward lupin (45). $R$. solani AG-2-2 was pathogenic on all the rotation crops, even though previous studies have reported it as being pathogenic only to- ward wheat and clover $(34,50)$. R. solani AG-4 HG-II was highly virulent toward lupin, medic, clover, and canola. $R$. solani AG-4, of which the subgroup has not been specified, is a well-known pathogen of canola $(11,12,14,16,17,46,53)$ and lucerne $(16,47)$, and also previously has been found pathogenic to lupin (26), medic (13), and clover (32).

Some of the R. solani AGs (e.g., AG-2-2 and AG-4-HG-II) were shown to be pathogenic to some of the test crops, but were never isolated from these crops in the field trial. This could be indicative of some biotic or abiotic factors within the rotation trial that are suppressing infection or populations of these AGs. Prolonged monoculture of lucerne within the trial site could have induced this disease suppression (29). Another factor contributing to the absence of these pathogenic multinucleate isolates could have been due to lucerne residue that can in itself suppress pathogenic Rhizoctonia spp. (43).

R. solani AG-3 and AG-11 were only weakly to moderately virulent on some of the crop plants tested. AG-3 was weakly virulent on canola, lupin, and medic seedlings, and this is the first report of AG-3 functioning as a pathogen in association with these crops. A previous report had indicated that AG-3 is not pathogenic towards lupin (21).

$R$. solani AG-11 has been reported as a pathogen of lupin (45) and, in our studies, was most virulent on this plant host. Isolates of this AG were weakly to moderately virulent on all other test crops, with the exception of barley and wheat. This appears to be the first report of AG-11 as a pathogen of canola, clover, medic, and lucerne worldwide.

Knowledge of the appropriate inoculum concentration is of utmost importance to differentiate pathogenicity and relative virulence among Rhizoctonia isolates. Inoculum concentrations that are too high can result in an inability to distinguish between highly virulent isolates, whereas a too-low inoculum concentration can result in an inability to distinguish among weakly virulent isolates. In these trials, $0.05 \%$ (wt/wt) inoculum concentration was found most appropriate for determining pathogenicity and relative virulence of Rhizoctonia AGs on emerging seedlings of wheat and canola.

Plant assays clearly demonstrated that the relative virulence of Rhizoctonia isolates is influenced by inoculum concentration utilized. Consequently, differences in inoculum concentration used in various other studies $(3,25,31,45,52)$ could explain discrepancies in the pathogenicity of some AGs on certain crops as determined in this study, relative to previous reports. Additional factors influencing apparent virulence include host cultivar and environmental conditions (40). Therefore, future studies should evaluate more cultivars of the currently evaluated rotation crops. Furthermore, it is important that future studies should establish inoculum concentrations of specific AGs in natural soil ecosystems using techniques such as quantitative real-time PCR.

Determining Rhizoctonia AGs associated with rotation crops is essential for development of effective integrated management strategies, including crop rotation and seed treatments. This is especially important because the identification and confirmation of pathogenicity of the various AGs toward the seven rotation crops evaluated in this study suggest that Rhizoctonia spp. are contributing to difficulties in seedling establishment of these crops observed in the Western Cape region of South Africa (S. C. Lamprecht, E. E. Auret, and J. C. Janse van Rensburg, unpublished data). The identification of specific pathogenic AGs will allow for the evaluation of different fungicide seed treatments for control of these AGs (16), because Rhizoctonia spp. of different AGs can differ in sensitivity to the same fungicide (15). Knowledge of the host range of each AG also will allow for the development of appropriate crop sequences to be used in rotation systems.

\section{ACKNOWLEDGMENTS}

We thank the Protein Research Foundation (South Africa), the United States Department of Agriculture-Agricultural Research Service, and University of Stellenbosch for providing financial support for this project; A. Schoeman, A. van den Heever, A. Hendricks, and J. Deysel for technical assistance; and F. Calitz for statistical analysis of the data.

\section{LITERATURE CITED}

1. Adams G. C. 1988. Thanatephorus cucumeris (Rhizoctonia solani), a species complex of wide host range. Pages 535-552 in: Advances in Plant Pathology: Genetics of Plant pathogenic Fungi. D. S. Ingram and P. H. William, eds. Academic Press, London.

2. Anderson, N. A. 1982. The genetics and pathology of Rhizoctonia solani. Annu. Rev. Phytopathol. 20:329-347.

3. Botha, A., Denman, S., Lamprecht, S. C., Mazzola, M., and Crous, P. W. 2003. Characterisation and pathogenicity of Rhizoctonia isolates associated with black root rot of strawberries in the Western Cape province of South Africa. Australas. Plant Pathol. 32:195-201.

4. Bretag, T. W. 1985. Fungi associated with root rots of annual Medicago spp. in Australia. Trans. Br. Mycol. Soc. 85:329-334.

5. Carling, D. E. 1996. Grouping in Rhizoctonia solani by hyphal anastomosis reaction. Pages 37-47 in: Rhizoctonia Species: Taxonomy, Molecular Biology, Ecology, Pathology and Disease Control. B. Sneh, S. Jabaji-Hare, S. Neate, and G. Dijst, eds. Kluwer Academic Publisher, Dordrecht, The Netherlands.

6. Carling, D. E., Kuninaga, S., and Brainard, K. A. 2002. Hyphal anastomosis reactions, rDNA-internal transcribed spacer sequences, and virulence levels among subsets of Rhizoctonia solani anastomosis group-2 (AG-2) and AG-BI. Phytopathology 92:43-50.

7. Carling, D. E., Pope, E. J., Brainard, K. A., and Carter, D. A. 1999. Characterization of mycorrhizal isolates of Rhizoctonia solani from an orchid, including AG-12, a new anastomo- 
sis group. Phytopathology 89:942-946.

8. Carling, D. E., Rothrock, C. S., MacNish, G. C., Sweetingham, M. W., Brainard, K. A., and Winters, S. W. 1994. Characterization of anastomosis group 11 (AG-11) of Rhizoctonia solani. Phytopathology 84:1387-1393.

9. Carling, D. E., and Sumner, D. R. 1992. Rhizoctonia. Pages 157-165 in: Methods for Research on Soilborne Phytopathogenic Fungi. L. L. Singleton, J. D. Mihail, and C. M. Rush, eds. American Phytopathological Society, St. Paul, MN.

10. Glass, G. V., Peckham, P. D., and Sanders, J. R. 1972. Consequences of failure to meet assumptions underlying the fixed effects analyses of variance and covariance. Rev. Edu. Res. 42:237-288.

11. Gugel, R. K., Yitbarek, S. M., Verma, P. R., Morrall, R. A. A., and Sadasivaiah, R. S. 1987. Etiology of the Rhizoctonia root rot complex of canola in the Peace River region of Alberta. Can. J. Plant Pathol. 9:119-128.

12. Hwang, S. F., Swanson, T. A., and Evans, I. R. 1986. Characterization of Rhizoctonia solani isolates from canola in West Central Alberta. Plant Dis. 70:681-683.

13. Johnk, J. S., and Jones, R. K. 1993. Differentiation of populations of AG-2-2 of Rhizoctonia solani by analysis of cellular fatty acids. Phytopathology 83:278-283.

14. Kaminski, D. A., and Verma, P. R. 1985. Cultural characteristics, virulence, and in vitro temperature effect on mycelial growth of Rhizoctonia isolates from rapeseed. Can. J. Plant Pathol. 7:256-261.

15. Kataria, H. R., and Gisi, U. 1996. Chemical control of Rhizoctonia species. Pages 537-547 in: Rhizoctonia Species: Taxonomy, Molecular Biology, Ecology, Pathology and Disease Control. B. Sneh, S. Jabaji-Hare, S. Neate, and G. Dijst, eds. Kluwer Academic Publishers, Dordrecht, The Netherlands.

16. Kataria, H. R., and Verma, P. R. 1990. Efficacy of fungicidal seed treatments against preemergence damping-off and post-emergence seedling root rot of growth chamber grown canola caused by Rhizoctonia solani AG-2-1 and AG-4. Can. J. Plant Pathol. 12:409-416.

17. Kataria, H. R., and Verma, P. R. 1992. Rhizoctonia solani damping-off and root rot in oilseed rape and canola. Crop Prot. 11:8-13.

18. Khangura, R. K., Barbetti, M. J., and Sweetingham, M. W. 1999. Characterization and pathogenicity of Rhizoctonia species on canola. Plant Dis. 83:714-721.

19. Kronland, W. C., and Stanghellini, M. E. 1988. Clean slide technique for the observation of anastomosis and nuclear condition of Rhizoctonia solani. Phytopathology 78:820-822.

20. Lamprecht, S. C., Knox-Davies, P. S., and Marasas, W. F. O. 1988. Fungi associated with root rot of annual Medicago spp. in South Africa. Phytophylactica 20:281-286.

21. Leach, S. S., and Clapham, W. M. 1992. Rhizoctonia solani on white lupin. Plant Dis. 76:417-419.

22. Lee, S. B., and Taylor, J. W. 1990. Isolation of DNA from fungal mycelia and single spores. Pages 282-287 in: PCR Protocols: A Guide to Methods and Applications. M. A. Inni, D. H.
Gelfand, J. J. Sninsky, and T. J. White, eds. Academic Press, San Diego, CA.

23. Levene, H. 1960. Robust test in the equality of variance. Pages 278-292 in: Contributions to Probability and Statistics. I. Olkin, ed. Stanford University Press, Palo Alto, CA.

24. Little, T. M., and Hills, F. J. 1972. Statistical Methods in Agriculture. University of California, Davis.

25. MacLeod, W. J., and Sweetingham, M. W. 1997. A root disease of Lupinus angustifolius caused by a new species of binucleate Rhizoctonia. Aust. J. Agric. Res. 48:21-30.

26. MacNish, G. C., Carling, D. E., and Brainard, K. A. 1993. Characterization of Rhizoctonia solani AG-8 from bare patches by pectic isozyme (Zymogram) and anastomosis techniques. Phytopathology 83:922-927.

27. MacNish, G. C., Carling, D. E., Sweetingham, M. W., Ogoshi, A., and Brainard, K. A. 1995. Characterisation of anastomosis group-10 (AG-10) of Rhizoctonia solani. Australas. Plant Pathol. 24:252-260.

28. Mazzola, M. 1997. Identification and pathogenicity of Rhizoctonia spp. isolated from apple roots and orchard soils. Phytopathology 87:582-587.

29. Mazzola, M. 2002. Mechanisms of natural soil suppressiveness to soilborne diseases. Antonie Leeuwenhoek 81:557-564.

30. Mazzola, M., Wong, O. T., and Cook, R. J. 1996. Virulence of Rhizoctonia oryzae and $R$. solani AG-8 on wheat and detection of $R$. oryzae in plant tissue by PCR. Phytopathology 86:354-360.

31. Ogoshi, A., Cook, R. J., and Bassett, E. N. 1990. Rhizoctonia species and anastomosis groups causing root rot of wheat and barley in the Pacific Northwest. Phytopathology 80:784788.

32. Pemberton, I. J., Smith, G. R., Philley, G. L., Rouquette, F. M., Jr., and Yuen, G. Y. 1998. First report of Pythium ultimum, P. irregulare, Rhizoctonia solani AG-4, and Fusarium proliferatum from arrowleaf clover (Trifolium vesiculosum): a disease complex. Plant Dis. 82:128.

33. Pumphrey, F. V., Wilkins, D. E., Hane, D. C., and Smiley, R. W. 1987. Influence of tillage and nitrogen fertilizer on Rhizoctonia root rot (bare patch) of winter wheat. Plant Dis. 71:125-127.

34. Rush, C. M., Carling, D. E., Harveson, R. M., and Mathieson, J. T. 1994. Prevalence and pathogenicity of anastomosis groups of Rhizoctonia solani from wheat and sugar beet in Texas. Plant Dis. 78:349-352.

35. Samuel, G., and Garret, S. D. 1932. Rhizoctonia solani on cereals in South Australia. Phytopathology 22:827-836.

36. Scott, D. B., Visser, C. P. N., and Rufenacht, E. M. C. 1979. Crater disease of summer wheat in African dry lands. Plant Dis. Rep. 63:836-840.

37. Shapiro, S. S., and Wilk, M. B. 1965. An analysis of variance test for normality (complete samples). Biometrika 52:591-611.

38. Smiley, R. W., and Uddin, W. 1993. Influence of soil temperature on Rhizoctonia root rot $(R$. solani AG-8 and $R$. oryzae) of winter wheat. Phytopathology 83:777-785.
39. Smith, E. M., and Wehner, F. C. 1986. Induction of crater disease of wheat in the field by artificial infestation of the soil with Rhizoctonia solani. Phytophylactica 18:127-130.

40. Smith, J. D., Kidwell, K. K., Evans, M. A., Cook, R. J., and Smiley, R. W. 2003. Assessment of spring wheat genotypes for disease reaction to Rhizoctonia solani AG-8 in controlled environment and direct-seeded field evaluation. Crop Sci. 43:694-700.

41. Snedecor, G. W., and Cochran, W. G. 1967 Statistical Methods, Sixth Edition. The Iowa State University Press, Ames.

42. Sneh, B., Burpee, L., and Ogoshi, A. 1991. Identification of Rhizoctonia Species. American Phytopathological Society Press, St. Paul, MN.

43. Sneh, B., Jabaji-Hare, S., Neate, S., and Dijst, G. 1996. Rhizoctonia Species: Taxonomy, Molecular Biology, Ecology, Pathology and Disease Control. Kluwer Academic Publishers, Dordrecht, The Netherlands.

44. Strauss, J., and Labuschagne, N. 1995. Pathogenicity of Fusarium solani isolates on citrus roots and evaluation of different inoculum types. Toegepaste Plantwetenskap 9:48-52.

45. Sweetingham, M. W., Cruickshank, R. H., and Wong, D. H. 1986. Pectic zymograms and taxonomy and pathogenicity of the Ceratobasidiaceae. Trans. Br. Mycol. Soc. 86:305-311.

46. Teo, B. K., Yitbarek, S. M., Verma, P. R., and Morrall, R. A. 1988. Influence of soil moisture, seeding date, and Rhizoctonia solani isolates (AG-2-1 and AG-4) on disease incidence and yield in canola. Can. J. Plant Pathol. 10:151-158.

47. Vincelli, P. C., and Herr, J. J. 1992. Two diseases of alfalfa caused by Rhizoctonia solani AG-1 and AG-4. Plant Dis. 76:1283.

48. Weller, D. M., Cook, R. J., MacNish, G. C. Basset, E. N., Powelson, R. L., and Peterson, R. R. 1986. Rhizoctonia root rot of small grains favored by reduced tillage in the Pacific Northwest. Plant Dis. 70:70-73.

49. White, T. J., Bruns, T., Lee, S., and Taylor, J. 1990. Amplification and direct sequencing of fungal ribosomal RNA genes for phylogenetics. Pages 315-322 in: PCR Protocols: A Guide to Methods and Applications. M. A. Innis, D. H. Gelfand, J. J. Sninsky, and T. J. White, eds. Academic Press, San Diego, CA.

50. Wong, D. H., Barbetti, M. J., and Sivasithamparam, K. 1985. Pathogenicity of Rhizoctonia spp. associated with root rots of subterranean clover. Trans. Br. Mycol. Soc. 85:156-158.

51. Yamamoto, D. T., and Uchida, J. Y. 1982. Rapid nuclear staining of Rhizoctonia solani and related fungi with Acridine orange and with Safranin O. Mycologia 74:145-149.

52. Yang, H. A., Sivasithamparam, K., Alemohammad, J., Barton, J. E., and O'Brien, P. A 1994. Association of Rhizoctonia strains with bare patch disease of wheat in Western Australia. Plant Pathol. 43:878-884.

53. Yitbarek, S. M., Verma, P. R., and Morrall, R. A. A. 1987. Anastomosis groups, pathogenicity, and specificity of Rhizoctonia solani isolates from seeding and adult rapeseed / canola plants and soils in Saskatchewan. Can. J. Plant Pathol. 9:6-13. 